\title{
Duplicated internal auditory canal with dysplastic ossicles and microtia: role of high-resolution CT and MRI
}

\author{
Priya Singh, ${ }^{1}$ Amrin Israrahmed, ${ }^{2}$ Javed Akhter, ${ }^{2}$ Hira Lal (i) ${ }^{2}$
}

${ }^{1}$ Radiology, King George Medical College, Lucknow, Uttar Pradesh, India

${ }^{2}$ Radiodiagnosis, Sanjay Gandhi Post Graduate Institute of Medical Sciences, Lucknow, India

Correspondence to Dr Hira Lal; hiralal2007@yahoo.co.in

Accepted 4 May 2021

Check for updates

(c) BMJ Publishing Group Limited 2021. No commercial re-use. See rights and permissions. Published by BMJ.

\footnotetext{
To cite: Singh $P$,

Israrahmed A, Akhter J,

et al. BMJ Case Rep

2021:14:e243825.

doi:10.1136/bcr-2021-

243825
}

\section{DESCRIPTION}

A 16-year-old girl with congenital hearing loss was referred to our department for radiological evaluation and feasibility for cochlear implantation. She had previously used various external hearing aids with no significant success. Her antenatal and postnatal history was normal with no family history of congenital or early-onset hearing loss.

Physical examination revealed shorter neck and bilateral grade 2 microtia (figure 1A,B) with normal external auditory canals. No syndromic stigmatalike pigmentary anomalies and craniofacial features were seen. Facial nerve functions were normal on both sides; however, her speech and language functions were markedly impaired. Complete audiological evaluation was suggestive of bilateral asymmetrical mixed hearing loss, and hence, the child underwent high-resolution CT (HRCT) temporal bone for further workup.

HRCT was performed on a 64-slice multidetector CT scanner (Philips Ingenuity, Philips Healthcare, Cleveland, Ohio, USA) which showed duplicated internal auditory canal (DIAC) on the right side, with a narrow posteroinferior and broader anterosuperior compartment. The posteroinferior canal ( $<1 \mathrm{~mm}$ diameter) was terminating into the cochlea and vestibule (figure $1 \mathrm{C}$ ), while the anterosuperior compartment was continuous with the facial canal (figure 1D). The two canals were separated by a bony septum (figure 1E). Bilateral ear ossicles were dysplastic (figure 1F). Inner ear structures including cochlear turns, vestibule and semicircular canals were normal on both sides. Left internal auditory canal (IAC) was normal. Bilateral external ears were small and deformed; however, external auditory canals were normal. Complete atlanto-occipital assimilation was seen (figure $1 G$ ). For further evaluation of the VII/VIII nerve complexes, MRI was done on 3 Tesla (SIEMENS, Germany) using threedimensional constructive interference in steady-state (CISS) images. MRI showed duplicated and narrow right IAC with non-visualisation of right cochlear nerve and normal facial nerve in the anterosuperior canal (figure 2). Other bilateral inner ear structures and left VII/VIII nerve complexes were normal. The absence of the cochlear nerve on the right side precluded the feasibility of cochlear implantation. Therefore, ossicular reconstruction of the left ear was advised for correcting conductive deafness, followed by plastic surgery consultation for correction of microtia.

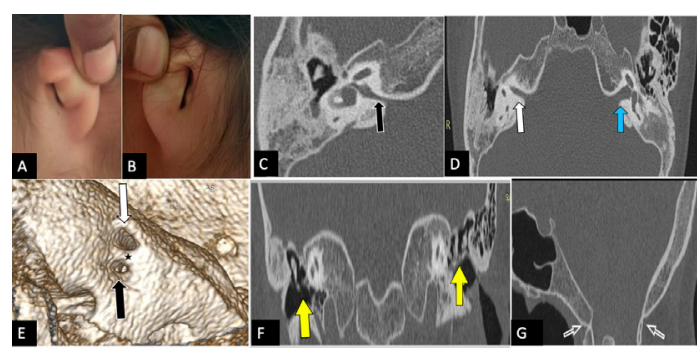

Figure $1 \quad(A, B)$ Clinical picture showing bilateral grade 2 microtia ( $A$, left ear; $B$, right ear). ( $C-G)$ High-resolution CT (HRCT) temporal bone. (C) HRCT axial image shows narrow posteroinferior canal (black arrow) terminating into cochlea and vestibule. (D) Axial image shows an anterosuperior canal (white arrow) terminating into the facial canal and normal left internal auditory canal (blue arrow). (E) Volume-rendered image of right petrous temporal bone shows duplicated right internal auditory canal (DIAC) separated by a horizontal bony septum (star). Anterosuperior facial nerve canal (white arrow) and narrow posteroinferior vestibulocochlear nerve canal (black arrow). (F) Coronal image shows dysplastic bilateral ear ossicles (yellow arrows). (G) HRCT in the mid-sagittal plane shows atlanto-occipital assimilation (hollow white arrows).

Duplication of IAC (DIAC) is a very rare anomaly with less than 50 cases reported in the literature. ${ }^{1}$ Imaging features of duplicated IAC and its

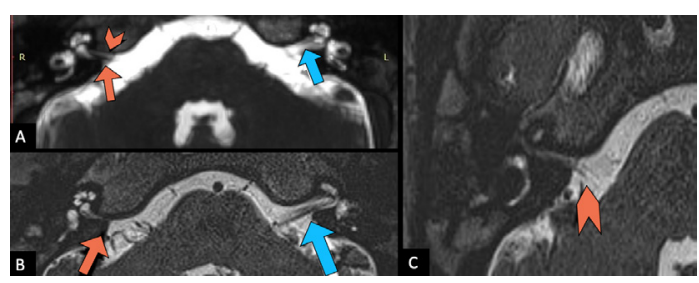

Figure 2 MRI of the inner ear. (A) Axial constructive interference in steady-state (CISS) image (thicker slice) shows duplicated right internal auditory canal (DIAC) with the anterosuperior canal (red arrowhead) terminating into the facial canal and narrow posteroinferior canal (red arrow) terminating into cochlea and vestibule. Normal internal auditory canal (IAC) on the left side (blue arrow). (B, C) Axial CISS images (thinner slices) demonstrate aplastic/hypoplastic right vestibulocochlear nerve (red arrow in B) and normal facial nerve in the right anterosuperior canal (red arrowhead in C). Normal vestibulocochlear/facial nerve complex in the left IAC (blue arrow in B). 
association with other ear malformations are not well understood. Duplication of IAC usually occurs unilaterally and is often associated with the aplastic/hypoplastic vestibulocochlear nerve. ${ }^{1}$ It is important to differentiate IAC stenosis from DIAC

\section{Patient's perspective}

We were very worried as our daughter was not able to hear and speak properly since birth. She tried multiple hearing aids without much benefit. We were referred to the hospital for the cochlear implant. After testing her ears with Audiometry, CT \& MRI, doctors told us that the cochlear implant will not be beneficial for her. However, they also explained to us that her left ear is relatively normal in which hearing could be improved by an operation. Due to my financial constraints, I am not able to get it done immediately. But I will surely get her operated as soon as finances are arranged. (Patient's father)

\section{Learning points}

- Duplication of the internal auditory canal (DIAC) is a very rare anomaly and produces a double canal appearance on cross-sectional imaging studies. The two canals are usually separated by a bony septum.

- Differentiation of IAC stenosis from DIAC is extremely important in appropriate selection of patients for electronic cochlear implantation because patients with IAC stenosis usually benefit from cochlear implantation than DIAC.

- In cases with hearing loss, DIAC is usually accompanied by other ear abnormalities. Thus, HRCT and MRI with multiplanar reconstruction and volume rendering are necessary for complete preoperative evaluation of DIAC and to rule out other associated syndromes. on imaging because patients with IAC stenosis have dysplastic vestibulocochlear nerve and they usually benefit from electronic cochlear implantation, while cases with DIAC have aplastic/ hypoplastic nerve and are usually not benefited from electronic cochlear implantation. ${ }^{23}$ External, middle and inner ear abnormalities are occasionally seen with DIAC which are additionally responsible for the hearing loss and need consideration while planning for surgery. ${ }^{1}$ Rarely, DIAC can be associated with syndromes like Klippel-Feil syndrome and pontine tegmental cap dysplasia. ${ }^{4}$ Thus, HRCT followed by MRI is necessary for the complete evaluation of cases of DIAC.

Acknowledgements We would like to thank the radiology department staff for coordinating the scans effectively.

Contributors The data collection was done by PS. The preliminary version of the manuscript was drafted by AI and PS. AI and JA formatted the figures and PS revised the figure legends. The final version of the manuscript was edited and supervised by $\mathrm{HL}$.

Funding The authors have not declared a specific grant for this research from any funding agency in the public, commercial or not-for-profit sectors.

Disclaimer Case reports provide a valuable learning resource for the scientific community and can indicate areas of interest for future research. They should not be used in isolation to guide treatment choices or public health policy.

Competing interests None declared.

Patient consent for publication Parental/guardian consent obtained.

Provenance and peer review Not commissioned; externally peer reviewed.

\section{ORCID iD}

Hira Lal http://orcid.org/0000-0001-7957-635X

\section{REFERENCES}

1 Wang L, Zhang L, Li X, et al. Duplicated internal auditory canal: high-resolution CT and MRI findings. Korean J Radiol 2019:20:823-9.

2 Binnetoğlu A, Bağlam T, Sarı M, et al. A challenge for cochlear implantation: duplicated internal auditory canal. J Int Adv Otol 2016;12:199-201.

3 Kariya S, Nishizaki K, Akagi H, et al. Abnormal direction of internal auditory canal and vestibulocochlear nerve. J Laryngol Otol 2004;118:902-5.

4 Demir OI, Cakmakci H, Erdag TK, et al. Narrow duplicated internal auditory canal: radiological findings and review of the literature. Pediatr Radiol 2005;35:1220-3.

Copyright 2021 BMJ Publishing Group. All rights reserved. For permission to reuse any of this content visit

https://www.bmj.com/company/products-services/rights-and-licensing/permissions/

BMJ Case Report Fellows may re-use this article for personal use and teaching without any further permission.

Become a Fellow of BMJ Case Reports today and you can:

- Submit as many cases as you like

- Enjoy fast sympathetic peer review and rapid publication of accepted articles

- Access all the published articles

Re-use any of the published material for personal use and teaching without further permission

Customer Service

If you have any further queries about your subscription, please contact our customer services team on +44 (0) 2071111105 or via email at support@bmj.com.

Visit casereports.bmj.com for more articles like this and to become a Fellow 